\title{
O Sentido da etnografia fílmica compartilhada de JeAn Rouch em "Crônicas de um verão"
}

Rodrigo Oliveira Lessa ${ }^{1}$

\begin{abstract}
O presente estudo analisa aspectos da produção cinematográfica documental e etnográfica do diretor Jean Rouch que giram em torno de uma de suas mais célebres obras, "Crônicas de Um Verão" (1961), realizada em parceria com Edgar Morin. Para a consecução deste escopo, situamos a iniciativa fllmográfica de Rouch no panorama da tradição audiovisual que envolve o campo do filme etnográfico, $e$, em seguida, analisamos de que maneira este cineasta repensou em "Crônicas" a relação entre o sujeito e o objeto da representação, na imagem do filme etnográfico, agregando referências do documentário a uma concep̧̧ão particular de Antropologia Compartilhada para dar origem ao Cinema Verdade francês.
\end{abstract}

Palavras-chaves: antropologia visual; filme etnográfico; antropologia compartilhada; cinema verdade

Uando procuramos refletir sobre campo das realizações da obra de Jean Rouch enquanto documentarista, o primeiro ponto importante a ser notado é que o estilo que surgiu em meio às questões e inovações que ele apresentou encontram forte referência nos debates que deram origem aos métodos clássicos do filme etnográfico e mesmo da Antropologia enquanto ciência. Até a repercussão estética e epistemológica do Cinema Verdade na década de 1960, uma longa trajetória de discussões sobre a representação do "outro" enquanto objeto e mais tarde até como sujeito do conhecimento - até um certo ponto uma das pretensões do filme que iremos analisar - vinham sendo travadas, repercutindo em polêmicas que reverberaram no surgimento do campo da Antropologia Visual. É importante por isso, antes de tudo, situar este debate para em seguida entender qual proposta carrega a narrativa de Crônicas e o Cinema Verdade francês que se desenvolveria a partir dali.

1 UFBA, Salvador, BA, Brasil. Contacto: rodrigo.ciso@gmail.com 


\section{OS CAMINHOS DA CRÍTICA À INSERÇÃo SUBJETIVA NO FILME ETNOGRÁFICO}

A Antropologia, como sabemos, é uma criação da doutrina humanista inaugurada pelo século do séc. XVIII, basicamente a partir das formulações filosóficas inerentes ao Iluminismo. A partir deste momento passou a ser fundamental sistematizar de forma racional o conhecimento humano nos seus mais diversos desdobramentos, o que inclui aqui o próprio indivíduo em sua diversidade. Tornava-se fundamental também, nesta linha, sistematizar todo o conhecimento sobre "o outro", ou seja, os não-europeus; distantes no espaço, é verdade, mas que vinham a ser simbolicamente próximos o bastante para serem tomados como ameaças.

Contudo, é com a doutrina Evolucionista que perpassa a segunda metade do século XIX que a alteridade se transforma definitivamente num problema epistemológico, o que termina inclusive rompendo com a antiga ideia de uma natureza humana, cunhada por autores como Jean Jacques Rousseau. Aquele que antes era visto como selvagem passa agora a ser analisado como um indivíduo "primitivo", relativamente semelhante ao homem civilizado europeu - apesar de encontrar-se num outro patamar de desenvolvimento da civilização humana como proferia o pensamento evolucionista da época. Com a força de uma reflexão mais contextualizadora, a história da humanidade passa a ser concebida como uma série de estágios sucessivos de desenvolvimento dos grupos sociais e os chamados povos primitivos cada vez mais surgiam nas indagações como remanescentes das etapas iniciais deste desenvolvimento. As expedições etnográficas de pesquisadores como Alfred Haddon, C. G. Seligman e, mais tarde, Franz Boas e Bronislaw Malinowski, tornam-se cada vez mais recorrentes no exercício da busca do longínquo e da catalogação do passado presentificado nestes povos em diferentes etapas no desenvolvimento da civilização humana. É aqui que surge definitivamente a etnografia enquanto convergência do papel do observador cultural com o do analista, quando exige-se do pesquisador que se faça presente no seu campo de pesquisa.

Com Boas, o pesquisador é não só levado a estudar ele mesmo a cultura que the serve de objeto, como também passa a buscar viver entre seus agentes, falando a língua destes e procurando entender o mundo tal como estes o entendiam. $\mathrm{O}$ universo simbólico da outra cultura precisava ser assim anotado meticulosamente, mesmo onde pareciam existir apenas gestos corriqueiros e insignificantes. Já Malinovski, que diferentemente de Boas produziu uma obra escrita de grande monta e uma teoria concisa a partir dela, reinventou com Os Argonautas do Pacífico Ocidental (1922) a prática de inserção num grupo social estudado ao quase romper com as ligações europeias nas estadias sucessivas das ilhas Trobiand. Além de dar um destaque mais enfático ao universo da cultura local estudada, considerando-a como uma totalidade complexa ou uma micro-sociedade que funciona a partir de elementos presentes que a mantém viva (Laplatine 2007).

Ainda no início do séc. XX, fatos históricos levaram a significativas transformações, dando os primeiros frutos emblemáticos ao campo do filme etnográfico. As ciências e as artes adentraram num período de novas buscas metodológicas, estéticas e linguísticas, criando novas formas de pensamento e conhecimento para a representação do mundo, este também imerso em crises e turbulências. Com a Primeira Guerra Mundial, os modelos evolucionistas começam a ser colocados em xeque e a sua barbárie é evidenciada, levantando críticas intensas à tradição evolucionista. Neste substrato histórico, o filme Nanook, O Esquimó (1922), de Robert Flaherty, surge como uma das primeiras realizações de uma narrativa relativamente distinta da ficcional e com uma forma nova de registrar a cultura, tornando-se mais tarde uma referência tanto para 
a tradição do cinema documental quanto a do filme etnográfico. Para Flaherty, era preciso criar um novo método de realização fundado no instrumento audiovisual, capaz de perceber estes povos nos seus próprios termos. Com o registro do cotidiano do esquimó Allakariallak, em Nanook, Flaherty introduz o conceito de câmera participante, tomando parte não só de eventos registrados como também procurando refletir os registros a partir das perspectivas dos nativos algo que Rouch inclusive tomará mais tarde como um dos seus principais paradigmas estéticos. A inovação o levou a um método que pode ser considerado como o do "presente etnográfico", dedicado a fazer emergir a história da cultura acompanhada a partir do próprio material de campo, reconstruindo os termos deste mundo social singular a partir de uma perspectiva, em muitos sentidos, dedicada a apreender elementos estáveis característicos desta cultura em sua forma fixa (Da-Rin 2007; Barbosa e Cunha 2006).

A partir da década de 1930, instaura-se uma a separação mais pronunciada da produção antropológica em duas categorias: aquela que agregava os filmes considerados como "etnografias científicas" e aqueles denominados como "filmes documentários", sobretudo porque este último já despontava como gênero iminente no campo do próprio cinema. John Grierson, Dziga Vertov e o próprio Flaherty, assim como o brasileiro Alberto Cavalcanti, vinham sendo gradativamente reconhecidos como diretores pioneiros de uma narrativa fílmica que já era capaz de demarcar suas fronteiras diante do cinema ficcional, mas que permaneciam reivindicando uma linguagem e um gênero no campo da arte cinematográfica. De todo modo, apesar desta separação - até natural em razão do viés estético cada vez mais pronunciado no documentário - diversos pesquisadores e realizadores da etnografia científica insistiram em manter o diálogo e compartilhar as polêmicas, firmando-se também como as figuras que contribuíram para consolidar o campo do filme etnográfico e fazê-lo avançar nas suas discussões a partir deste diálogo. São eles Margaret Mead, Gregory Bateson, o casal David e Judith MacDougall, e Jean Rouch, além de outros pesquisadores que assumem também um papel importante neste meio, como Timothy Asch, Jay Ruby, Asen Balikci, Robert Gardner e John Marshall. ${ }^{2}$

Margareth Mead e Gregory Bateson fizeram entre os anos de 1936 e 1939 seus estudos de campo sobre comportamento em Bali, na Indonésia, produzindo dezenas de fotografias e horas de filmes sobre as populações lá existentes. Nesta experiência pioneira, o registro visual tinha o objetivo primordial de apreender e compreender aquilo que poderia se configurar como o ethos balinês. A pesquisa não procurava entender tanto os costumes balineses, mas sim o indivíduo balinês, ou mais propriamente como ele incorporaria esta abstração que chamamos atualmente "cultura" por meio dos gestos, olhares e movimentos empenhados em seu cotidiano. Ao seguirem as orientações metodológicas de Marcel Mauss e também de Franz Boas, Mead e Bateson buscavam as relações e os comportamentos presentes nas regras culturais construídas em meio a elementos da comunicação não verbal, tais como padrões gestuais e corporais nas relações intra-familiares, nas condutas pautadas na consideração mútua, no respeito, na hierarquia, etc. No contexto da obra, este registro assumia o papel de suporte para a preservação documental de registros das expressões visuais dos padrões culturais que estariam fadados à extinção com o tempo. O cinema e a fotografia eram vistos como instrumentos poderosos de apreensão imagética objetiva da cultura em sua manifestação cotidiana, e os dois acreditavam numa complementaridade ainda não completamente alcançada pela antropologia entre a narrativa verbal e a não

2 Optamos por centrar a cronologia nos primeiros pela razão de terem se mantido como as principais figuras no âmbito das questões que lançaram em cada momento em particular do desenvolvimento da tradição audiovisual etnográfica. 
verbal da cultura dos povos, questão esta diretamente envolvida com a concepção polissêmica da imagem (Mead 1995).

Portanto, como podemos notar, este legado levou a Antropologia a um grande momento na história da etnografia. Com Mead e Bateson abraçando o uso do filme enquanto parte integrante de qualquer programa de pesquisa, funda-se o campo que mais tarde, nos anos 1980, viria a ser reconhecido como Antropologia Visual, sobretudo através do livro Balinese Character: a photografic analysis (1942) (Balikci 1989). Entretanto, eles contribuíram também para que nesta oportunidade a Antropologia alterasse de forma definitiva a sua postura em relação ao conhecimento etnográfico.

Se no início a Antropologia era vista predominantemente como um registro direto da realidade, produzida por alguém que teria autoridade moral e científica para falar sobre o nativo, com Boas e Mead, sobretudo, passou-se a considerar e problematizar abertamente o fato de o cientista se reconhecer na posição de um analítico da cultura, seja através da análise escrita ou do registro audiovisual. As repercussões destas duas contribuições geraram então uma polêmica epistemológica, que seguiria para as gerações seguintes reverberando em profundas discussões. A partir dali, o antropólogo passa a ser um indivíduo que carrega o peso do medo de estar a todo momento operando como um inconsciente ideológico manipulador da sociedade que pretende registrar e compreender. Assumir uma postura diante desta questão era então não só um imperativo metodológico, mas algo que passava também a influenciar na própria credibilidade do material que estava para ser produzido e divulgado.

\section{A alternativa de "Crônicas"}

É então na resposta o fato de o cientista ser levado a se reconhecer na posição de um analítico da cultura e carregar o peso do medo de estar a todo momento operando como um inconsciente ideológico, - firmada sobretudo através da obra de Margaret Mead de Gregory Bateson - que podemos encontrar e compreender melhor as questões que permearam o campo do filme etnográfico nas décadas de 1950 e 1960 e também a obra de Jean Rouch. De um lado, tivemos produções e pesquisadores que optaram por assumir o peso de conviver com este inconsciente ideológico e permanecer confiando no exercício de registrar e compreender a cultura do "outro" sem recorrer a um esforço auto reflexivo. É o caso do casal David e Judith MacDougall. Com uma proposta distinta da de Rouch, os MacDougall tentaram aliar a perspectiva do Cinema Direto norte-americano de Robert Drew à inspiração da etnografia clássica de Malinowski, cuja atenção se voltava para a vida cotidiana, seguindo a linha do observational cinema, ou cinema de observação. Preocupados com o desenrolar da ação propriamente dita e com a possibilidade de refletir a respeito dos seus significados para os sujeitos do filme, os filmes dos MacDougall mantinham o cineasta sempre fora do campo de visão do espectador, embora ativamente inseridos nas circunstâncias que davam origem às imagens. $\mathrm{O}$ trabalho dos MacDougall pregava a constante reavaliação dos objetivos e estratégias, mantendo uma postura altamente reflexiva que Rouch também desenvolveu. Mas não na imagem do filme, não durante o registro do comportamento, da expressão e da comunicação do nativo.

Jean Rouch, apesar de nutrir-se também destas referências, tem em sua obra uma estética e uma concepção de registro etnográfico que traz novos horizontes ao rol de possibilidades 
dessas posturas. Além de ser um admirador da estética de Flaherty, Rouch era muito ligado à proposta do Kino-Pravda (Câmera-Olho) de Dziga Vertov e via com curiosidade a estratégia de desconstrução que o russo utilizou contra o teor de fantasia do cinema ficcional da época ao escancarar a dimensão autoral que cria o filme. Em Um Homem Com Uma Câmera (1929), por exemplo, Vertov inseria imagens de bastidores e do operador da câmera nas películas para firmar uma perspectiva de registro sem cortinas, sem estórias, partindo apenas do próprio movimento da vida real cotidiana. A partir desta referência no campo do documentário, Rouch desenvolverá junto com Edgar Morin, em Crônicas, uma proposta de reavaliação constante desta postura autoral no filme. Mas, agora, com outro objetivo: o de se aprofundar nos termos pelos quais a relação íntima entre o pesquisador e o nativo, ou melhor, entre cineasta e personagem, se manifestam no filme, e se elas contribuem ou não para revelar as particularidades e a interioridade do último, na condição de personagem. Sem se darem por satisfeitos com a afirmada inevitabilidade da relação condicionada entre sujeito/objeto, mas também sem um horizonte muito claro sobre os possíveis resultados da nova experiência, Rouch e Morin vão acompanhados da intuição e do espírito de experimentalismo para realizar um cinema que continuasse reavaliando esta relação e as suas implicações para o conteúdo e a forma do filme. E tudo isso por uma razão bem simples: como eles sabiam que a relação entre sujeito e objeto era inevitável, optaram por trazê-la para a narrativa e analisá-la em seu objetivo maior dentro do filme etnográfico, o de revelar "o outro" na imagem filme.

Para Paul Henley (2006), dentre todas as obras da cinematografia de Jean Rouch, o filme que escolhemos aqui para aprofundar nossa compreensão nos aspectos desta concepção de cinema de Rouch é extremamente singular para esta linha do cinema etnográfico. E isso por uma razão bem específica, que na verdade atesta o forte grau de radicalização do método desta experiência: em Crônicas, Rouch, verdadeiro dominador da arte de filmar, se veria obrigado a dividir a autoria do filme com um número significativo de indivíduos/personagens, e mais notavelmente com o seu co-realizador imediato, o sociólogo Edgar Morin. Como resultado deste contexto, o filme se configurou como uma tentativa corajosa de buscar uma nova postura diante do verdadeiro emaranhando dos vários interesses de representação e problematização dos temas e questões levantados em detrimento da sobreposição de uma visão autoral majoritária sob a narrativa fílmica, ainda que os diretores tivessem tentado, sem sucesso, implantar sozinhos suas ambições originais na edição final do material.

A ideia do filme teria vindo mesmo, na verdade, do sociólogo Edgar Morin. Em dezembro de 1959, enquanto participava do primeiro Festival dei Popoli em Florença, na Itália, como membro do júri da seção etnográfica, Morin esboçou o interesse de realizar um filme fundado nos preceitos do cinema de Dziga Vertov, que apreendia aspectos essenciais da vida humana de uma maneira muito espontânea e da forma com a qual elas se apresentavam no cotidiano. (Henley 2006). A proposta para a parceria teve sucesso também em função do próprio interesse de Rouch pelo cinema de Vertov e o consenso inicial apontou para a realização de uma espécie de psicodrama das relações interpessoais e representativas dos indivíduos, colocando no centro da iniciativa a ideia de encorajar os personagens do filme a verbalizar suas angústias em frente à câmera, sobretudo com a tentativa de levá-los a externalizar pontos de vista sobre as questões suscitadas neste exercício e revelar contornos ainda ocultos nos meandros mais profundos do seu imaginário. Rouch, é bem verdade, estava voltado ainda para os resultados que alcançara em Eu Um Negro (1958) e A Pirâmide Humana (1959); ainda permanecia dedicado ao registro destas performances orais dos personagens, interessado na aparência surrealista do inconsciente como elementos de sua principal motivação criativa. Ele não via ainda nesta nova forma de 
registro o que para Morin seria uma transformadora perspectiva psicanalítica, quase nos termos de uma consulta psicológica, trazendo as ideias e angústias do inconsciente à tona com o interesse de banir toda a carga repressiva ainda presente neste inconsciente aprisionado.

Estes dois pontos de vista distintos acerca de como deveria se dar efetivamente o exercício fílmico se transferiram então para a produção de Crônicas e, deste modo, contribuíram de forma central para o modo como o compartilhamento de interesses distintos de objetivação e representação de questões diversas se apresentou na narrativa documental desta obra. Ao ter definido a ideia do filme, Morin convida o então parceiro de diálogos e reflexões e lhe coloca seu principal interesse na realização do que, mais tarde, se tornaria o projeto de Crônicas: levar a cabo do início ao fim do filme uma estrutura de problematização que tinha na questão "como você vive?" sua ideia original. Morin pretendia que todo o material fosse produzido buscando reunir elementos e aspectos de como cidadãos franceses comuns enxergavam e se posicionavam frente a este questionamento. Já Rouch tinha outra posição: ele queria que o filme fosse estruturado não numa questão como esta, mas sim em princípios biográficos e cronológicos advindos dos próprios personagens durante as filmagens e as entrevistas. Isto ocasionou a presença insistente destes dois interesses na produção do filme, tendo em vista a influência que os dois exerceram do início ao fim de sua realização. Mas podemos perceber também um primeiro desdobramento importante da ideia de um cinema de autoria compartilhada intentado por Morin e Rouch: "In the event, the final version of the film represented a compromise between the respective positions of all the main parties." (Henley 2006: 89).

Este compartilhamento nos interesses de condução da narrativa do filme, que até o momento analisamos apenas no que diz respeito às intervenções de Jean Rouch e Edgar Morin para a composição da narrativa (mais tarde teremos a dos outros personagens), teve então seus desdobramentos sobre o arranjo que encontramos na narrativa da obra. Uma das cenas relocadas para atender à sugestão da estrutura temática de Morin foi a de Marceline e Nadine, quando as duas andam pelas ruas perguntando aos transeuntes se estes são felizes. As abordagens terminam gerando cenas com respostas às vezes surpreendentes, por conterem declarações muito particulares das pessoas entrevistadas, e às vezes decepcionantes, por demonstrarem a incapacidade dos transeuntes para romper a barreira de recusa à interação e contribuir para a discussão que as duas pretendiam levantar. Embora tenha sido realizada depois, a sequência de Marceline e Nadine foi trazida para o começo do filme de modo que a questão do Cinema Verdade e da experimentação para provocação da fala do outro pudesse assumir o foco central do registro fílmico, dando logo de início a tônica das imagens que se seguiriam a partir dali.

E assim, logo no início, a narrativa apresenta o seu verdadeiro pano de fundo. As respostas evasivas, a timidez dos transeuntes e mesmo a situação grotesca de um jovem estudante de filosofia, que diante da questão questiona as referências teóricas da questão e esbanja o livro que está lendo, compõem as situações que o filme carrega como cruciais. Se as discussões entre Rouch e Morin motivam o compartilhamento de pontos de vista sobre a realização do filme, isto se soma ao apreço que os dois tinham pelas entrevistas e diálogos para consolidar a escolha do verdadeiro protagonista do documentário: as negociações autorais para a revelação do outro na imagem do filme. "Ce qui m'avait frappé dans Chronique, ceétait également ce qui se passait à de certains moments devant la caméra, où des gens qui ne se connaissaient pas, ou qui ne connaissaient pas certains aspects d'euxmêmes, se découvraient tout à coup." (Rouch 1963: 2). 
Em seguida, temos novos exemplos da tentativa de produzir uma versão mais compartilhada e flexível das questões sobre a vida parisiense daquela época, e dentre as cenas do personagem Angelo, operário das fábricas Renault. Embora tenham sido realizadas no período de férias, tal qual as sequências de Saint Tropez, cenas como a da conversa íntima entre Angelo e Landry também são antecipadas, de modo a situar a reflexão de Angelo sobre este tema controverso na sua experiência individual como trabalhador metalúrgico. $\mathrm{O}$ operário tem uma série de posturas bem particulares e não raro contraditórias sobre a sua existência, sobre o quadro de exploração que sofre na fábrica e sobre o fato de ser pobre e não dispor da liberdade que deseja para existir - as quais, por sua vez, surgem claramente como a referência fundamental das perguntas que ele faz ao imigrante africano. Após alguns minutos em que apresenta uma visão crítica e pessimista sobre o comportamento consumista e apático de seus colegas de fábrica, por exemplo, Angelo resolve indagar Landry se ele não se incomoda com o fato de ser negro, ou ainda se ele mantém o complexo de inferioridade de seu povo. Uma circunstância que, como podemos acompanhar no filme, nos dá elementos para enxergar como é problemática a sua leitura sobre a questão do racismo, a qual soa bastante preconceituosa apesar da pertinência de suas angústias e frustrações como operário de uma grande indústria do capitalismo moderno.

E a estratégia de Rouch e Morin já nesta conversa entre os dois personagens chega a um de seus efeitos mais ricos, dando pistas da contribuição que ela daria mais tarde ao cinema etnográfico e ao campo do filme documentário. Ao invés de trazer ao espectador explicações em voice over de um narrador da equipe de produção, ou ainda declarações bem objetivas mas ainda assim deslocadas da expressividade verbal de um e de outro destes personagens sobre os temas do filme, o embate de ideias entre os dois traz à obra contradições profundas na existência dos entrevistados, que por sua vez se revelam em meio ao espaço mais aberto e compartilhado de fala que recebem. Posteriormente, o espectador se sentirá em condição de se posicionar diante desse mar de contradições, mesmo que elas surjam mais tarde nas afirmações dos próprios cineastas. No contexto deste recurso, já não há mais grande relevância no fato de personagens como Angelo e Landry alterarem ou não seu comportamento diante da câmera e dos autores do filme, ou ainda se Rouch e Morin estariam intervindo no conteúdo do filme como cineastas e sujeitos da pesquisa, tal qual a polêmica lançada pelas realizações de Mead e Bateson impôs ao campo do filme etnográfico. O fato é que há o registro de um embate, que envolve Morin e Rouch, certamente, mas que traz também a interação de Landry e Angelo revelando suas posturas diante de questões cruciais para a política de imigração e recepção de estrangeiros na Europa nas décadas de 1950-60. Diante delas e da forma com que elas se desdobram, sobretudo, a partir dos diálogos longos e em certas ocasiões reveladores, é possível suscitar críticas sobre a cordialidade artificial de Angelo, como também é possível problematizar uma postura excessivamente passiva de Landry às análises preconceituosas do operário. Aqui podemos afirmar certamente que, diante da proposta inicial, Rouch e Morin geraram reflexões interessantes com esta experiência.

Mas os resultados de uma experimentação como esta com certeza não poderiam ser integralmente coerentes e dar conta de uma polêmica de décadas no âmbito do cinema etnográfico, e as respostas não tardaram. O projeto de Crônicas foi debatido e tornou-se alvo de uma forte crítica que apontou os limites quanto ao paradigma que ensaia os termos de uma antropologia compartilhada de caráter eminentemente reflexivo, pautada numa divisão supostamente equilibrada (mas sempre suspeita) da dimensão autoral do filme com os mais diversos personagens envolvidos na trama. 
Apesar de Rouch e Morin, pautados na experiência de Flaherty, buscarem uma negociação dos resultados da narrativa com os sujeitos que dela participaram, abrindo espaço para que estes deem uma opinião a respeito das ideias e questões presentes no filme, sabemos que é sempre o olhar de Rouch ou de Morin que aparece mais claramente. Seria também por isso justo apontar contradições em declarações como a de Morin, no fim do filme, que afirma:

Ce film, à la différence du cinéma habituel, nous rentre dans la vie. Les gents sont dans le film comme dans la vie de touts les jours. C'est à dire qu'ils ne sont pas guidés, parce que nous n’avons pas guidé les spectateurs. On n’a pas dit : un tel est gentil, un tel est méchant. [...]. (Morin, Rouch 1961)

A posição de Morin, inclusive, nos remete à própria leitura que ele tinha do cinema e das possibilidades de uma ruptura com o cinema ficcional que certamente o influenciou na idealização do roteiro. Para o sociólogo, o cinema poderia recuperar a surpresa e a indignação da população contra as catástrofes da sociedade capitalista, mas esta possibilidade passaria longe do caráter de fantasia e alienação que a imagem do filme teria tomado a partir da herança ficcional clássica. Como observa Yoon (2007), Era preciso por isso romper com a "impressão de realidade" que gera a técnica do reflexo objetivo da câmera na forma com que ela vinha sendo usada até então, e isso para seguir na direção do desvendamento da psique, dos sentidos e dos símbolos que envolveriam o pensamento humano. Externalizar os processos que fundam o homem moderno, o "homem imaginário", como conceituou Edgar Morin (1970). Era este o papel do cinema para ele.

O caráter de negociação realmente existe e isso não queremos negar, como podemos observar no fato de que nem o diretor nem seu co-realizador puderam emplacar sozinhos suas ideias de representações das questões presentes na iniciativa do filme. Entretanto, devemos notar, é notória a contradição na afirmação de Morin ao fim do filme, pois em detrimento dele acreditar na construção de entrevistas mais espontâneas, com tempo e espaço para os personagens liberarem seus pensamentos e sua inibição, não há como não guiar ou dirigir o resultado destas interlocuções.

A proposta gerou, e ainda gera, reprovações e efeitos sobre a discussão da relação entre sujeito e objeto no registro fílmico para o documentário e para a etnografia audiovisual. Alguns anos após a sua realização, Peter Grahan (1964) acusou Crônicas e o método de seus realizadores de ser hesitante na aceitação de suas visões e do caráter condicionado de sua obra, apesar de colocar a objetividade das informações coletadas como um objetivo, como chegam a admitir no próprio diálogo da cena que fecha o filme. Segundo ele, houve uma recusa explícita diante da responsabilidade de aplicar a visão autoral sobre as imagens. A câmera não poderia jamais, neste sentido, garantir um registro verdadeiro dos fenômenos acompanhados sem a intervenção autoral, que é sempre necessária, e esta hesitação em admitir a intervenção teria levado à suposição de seus realizadores de terem produzido um retrato neutro (e por isso totalmente objetivo) da realidade. Para o autor, Rouch e Morin teriam visualizado no horizonte um desejo incontido por uma forma de registro absolutamente controlada diante dos fenômenos registrados.

Mais tarde, o desdobramento destas discussões lançaria ainda uma nuvem obscura sobre o desdobramento da polêmica e do próprio filme que a inspirou. Como nos mostra Noël Carrol (1996), a análise da inserção subjetiva dos autores do filme a partir do registro da negociação do processo de revelação do personagem virá a resultar numa designação geral de todas as obras não ficcionais enquanto dotadas de um ponto de vista subjetivo, o que as tornaria "subjetivas" no sentido de não serem muito mais do que a visão de mundo dos seus próprios realizadores 
sobre um determinado tema. Após ter lançado uma polêmica contra a subjetividade sem tê-la esgotado inteiramente, ou, ainda, levando a primeira controvérsia a outra ainda maior, o filme etnográfico, o cinema observacional, mas sobretudo o Cinema Verdade de Rouch e Morin instauraram de uma só vez o estímulo a uma série discussões, elucubrações e manobras conceituais. Tal discussão culminará, por conseguinte, na estigmatização de todo o filme de não ficção como marcadamente ou predominantemente "subjetivo" nesse sentido idiossincrático, não havendo por isso alternativa possível às propostas em relação à representação da realidade ou a construção de um cinema político. A objetividade seria, assim, um mero instrumento de retórica, fornecendo apenas uma referência intelectual coletiva que não apontaria para uma representação dos fenômenos culturais tal como eles se manifestam no mundo objetivo. É o vemos em autores de grande amplitude e consolidados no campo da teoria do cinema documentário, como Bill Nichols ${ }^{3}$.

Não obstante a coerência da crítica de Grahan, e também a lucidez de Carrol que percebeu a precipitação obscurantista de intelectuais do filme documentário - que tentaram expulsar a categoria da objetividade na primeira polêmica realmente forte que ela enfrentou no gênero cinematográfico em questão - é fundamental recuperar analisar a proposta de Rouch e Morin no que ela contém de mais rico em termos de contribuição para o filme etnográfico e as discussões sobre a relação entre sujeito e objeto no âmbito da pesquisa antropológica. É importante, neste sentido, marcar as contradições que de fato se apresentam nesta concepção, como fizeram Carrol e Grahan, mas também compreender a dimensão onde ela, de fato, transcende as concepções que lhe deram origem e fornece a sua maior contribuição: a da estética e técnica do registro etnográfico documental de interlocução participativa e reflexiva.

$\mathrm{Na}$ verdade, em primeiro lugar, afora as colocações realmente descuidadas e pretenciosas de Morin, não há em Crônicas a proposição clara e concisa de que se pretenda criar a partir daquelas estratégias um documentário reflexivo de caráter verdadeiramente neutro. Como não há também na narrativa do filme a proposição de que apresentar os seus realizadores (Rouch e Morin) como personagens garantiria ao espectador uma representação absolutamente controlada dos fatos. A crítica de Grahan, portanto, é relevante, mas apenas se a aplicamos ao contexto de interpretações suscitadas sobre a obra, como a que Carrol analisa, e à declarações contraditórias como as de Morin. Afirmar que o filme tem como característica a busca de uma visão claramente neutra seria ignorar a postura do cineasta responsável por Crônicas antes, durante e depois do filme. A estratégia do filme tinha um caráter de experimentação e por isso não estava salvaguardada por nenhum manifesto, declaração de conteúdos e intenções ou coisa do gênero. Se os seus realizadores tinham ou não em suas idiossincrasias esta pretensão quanto a uma antropologia compartilhada de caráter reflexivo, como acreditava Grahan (1964), o fato é que Crônicas não é uma evidência segura de que eles tinham esta linha de trabalho no horizonte. O filme não opta por uma objetividade pautada na postura da neutralidade axiológica, pois ele e sua estética não têm uma precisão epistemológica suficiente para isso. $\mathrm{O}$ próprio Rouch se afastou em muitos momentos deste tipo de registro, retornando aos documentários mais expositivos anos depois, a exemplo de Caça Ao Leão Com Arco (1965) e Tambores do Passado (1971). Além disso, ele é sempre claro em suas declarações ao garantir que o resultado dos filmes tem sim o seu ponto de vista como diretor sobre qual é a mais objetiva expressão da

3 "La objetividad funciona más como una retórica que como un ritual, aunque también en este contexto puede ayudar a formar una identidad colectiva entre aquellos que comparten una visión del lugar que debe ocupar la objetividad en un texto (como los directores de la modalidad de observación.” (Nichols 1993: 251). 
realidade. Quando questionado sobre o que pensa sobre o papel da montagem neste contexto de objetividade na captação do real pelo cinema, por exemplo, ele é direto.

Je ne pense rien. Je me pose des questions. Qu'est-ce qui se passe à ce moment-là ? Est-ce là, comme disait Rossellini, que se fait la création ? Certainement, car c'est le travail le plus dur. C'est un travail de montage où, finalement, on fait un choix entre des élements pour essayer d'exprimer quelque chose qui, à votre avis, qui, à mon avis, est l'expression de la réalité, mais qui est en fait extrêmement subjectif. Or la, très souvent, c'est du massacre. Moi, je le sais très bien. Si on veut une comparaison technique, c'est comme quand on essaie d'amenager un fleuve. (Rouch : 1963: 6-7)

Portanto, pelo próprio caráter experimental, a principal força deste filme não está nas concepções a respeito da objetividade ou da neutralidade axiológica, que são questionáveis como vimos no caso específico de Morin -, mas sim numa nova forma de captar declarações e revelações dos seus personagens a partir do embate com a subjetividade autoral de seus realizadores. A contribuição é eminentemente técnica e, certamente, estética. Apesar das dificuldades e restrições da proposta do compartilhamento da produção de significados no filme etnográfico de Rouch, é importante perceber como a absorção e a problematização de questões como a subjetividade, a intervenção autoral ideológica e a objetividade voltada para uma concepção etnocêntrica são levadas a outro patamar. Mais exatamente, onde se abre espaço no filme para o elemento da ambiguidade da narrativa, pondo-se na ordem do dia a convergência de intervenções diversas na produção do material fílmico a partir de uma postura autoral que mantém a obra mais aberta a esta participação "externa” ao domínio do diretor. A espontaneidade com que as interpelações são desenvolvidas, a disposição para ouvir os sujeitos/personagens nos filmes e o tempo maior para que estes se abram para o exercício de representação, a inexistência de um roteiro formal e fechado para o filme, e, por fim, a ideia de seguir as inspirações subjetivas do próprio autor, que se alteram durante os trabalhos, nos levam a refletir sobre as possibilidades de um filme etnográfico mais disposto a repensar suas próprias convicções a respeito do que é a realidade e como ela pode ser trazida às lentes etnográficas. Temos aqui, portanto, um avanço significativo de propostas como a do "presente etnográfico" de Flaherty, uma nova forma de lidar com o peso do inconsciente ideológico trazido à tona ao longo da experiência etnográfica ${ }^{4}$.

Como podemos observar, é deste modo que os filmes de Rouch podem ser considerados como partes de uma nova reflexão epistemológica sobre a condição e a qualidade da etnografia e do cinema que envolve uma série de questões caras a Antropologia. "Assim, o cinema de Rouch se inspira nos conceitos da Antropologia e sua Antropologia está inspirada na sua percepção das imagens e do cinema." (Gonçalves 2008: 22). Polêmicas como a do lugar do sujeito e do objeto na pesquisa, da subjetividade, da objetividade, do real, do ficcional, da alteridade, do trabalho de campo e da produção de conhecimento impulsionam há muito as discussões nas ciências sociais, e são exatamente elas que vêm à tona quando observamos, nos filmes de Rouch e em particular em Crônicas, as inovações técnicas e estéticas que apontam para elementos como a auto representação do diretor enquanto personagem do filme, o aprofundamento no evento da interação e do diálogo que constitui a realização fílmica, o compartilhamento das reflexões a respeito do resultado da trama que se desenvolve através das imagens, etc. Tudo isso teve, sem sombra de dúvida, um grande impacto sobre os métodos e práticas etnográficos, mas a obra de Jean Rouch

4 "But for all its many merits, it is a film that is positively awash with contradictions and ambiguities, many of which continue to trouble documentarists inspired by this example. There is, first of all, the striking contrast between the principles governing the process of production and those applied in the post-production phase. [...] Whatever their differences, they shared a commitment to the idea of making the film on the basis of spontaneity, without a formal script, following their own or their subjects inspirations." (Henley 2006: 91). 
deve compreendida a partir de sua inovação audiovisual no campo antropológico, realizando uma intersecção técnica e estética entre o filme etnográfico e o campo do cinema documentário de um modo geral, tendo ela aí a razão fundamental de sua contribuição. Como uma obra que ligou com maior envergadura as contribuições dos dois campos no âmbito do audiovisual e os levou a manterem um diálogo importante no que diz respeito aos modos de produzir um filme e as repercussões éticas, políticas e metodológicas deste exercício.

\section{CONSIDERAÇõES FINAIS}

Apesar de serem em alguns aspectos contraditórios no que diz respeito à concepção que parece estar por trás de seus objetivos quanto a uma antropologia de caráter compartilhado e reflexivo, Rouch e Morin contribuem com as reflexões epistemológicas e estéticas no âmbito da prática do cinema etnográfico. Eles convidam a dimensão subjetiva dos personagens - e isso inclui seus próprios realizadores - a uma exposição que ao menos tenha como meta reconhecer e abordar de forma mais profunda sua interioridade, suas contradições, suas crenças, suas intervenções e a sua responsabilidade na produção de sentido, concedendo-lhe uma nova posição enquanto objeto de registro fílmico. Com Rouch, em particular, o cinema documentário e o filme etnográfico ganham novas possibilidades para a realização da autocrítica subjetiva da dimensão autoral, tanto para a pesquisa em antropologia quanto para a realização do filme etnográfico predominantemente enquanto expressão artística, e ainda conseguem desenvolver um método novo de revelação da subjetividade dos atores sociais que ocupam a posição de personagens na imagem do filme etnográfico e do cinema documentário. É por este caminho que a compreensão do sentido de um cinema pautado na antropologia compartilhada de Jean Rouch se inicia.

\section{REFERÊNCIAS}

Balikci, Asen. 1989. "Film and Artic Peoples: the First Forman Lecture". Antropology Today 5(2): 4-10.

Barbosa, Andréa; Cunha, Teodoro. 2006. Antropologia e Imagem. Rio de Janeiro: Jorge Zahar Editor.

Carrol, Noël. Theorizing the Moving Image. 1996. New York: Cambridge.

Da-Rin, Silvio. 2004. Espelho Partido: Tradição e Transformação do Documentário. Rio de Janeiro: Azougue Editorial.

Gonçalves, Marco Antônio. 2008. O Real Imaginado: Etnografia, Cinema e Surrealismo em Jean Rouch. Rio de Janeiro: Topbooks.

Henley, Paul. 2006. The Adventure of The Real: Jean Rouch and the Craft of Ethnographic Cinema. Chicago: The University of Chicado Press.

Laplatine, François. 2007. Aprender Antropologia. São Paulo: Brasiliense.

Mead, Margaret. 1995. "Visual Anthropology in a Discipline of Words". Pp. 3-10 in Rethinking Visual Anthropology. 2003. Editado por Hockings, Paul. Berlin: De Gruyter.

Morin, Edgar. 1970. O Cinema Ou o Homem Imaginário: ensaio de antropologia. Lisboa: Moraes Editores.

Nichols, Bill. 2005 Introdução ao Documentário. Campinas: Papirus. 1993. La Reprentación de La Realidad. Barcelona: Paidós. 
Rouch, Jean. 1963. “Entretien avec Jean Rouch”. Cabiers du Cinéma 144(24) 1-22. Entrevista realizada por Eric Rohmer e Louis Marcorelles.

1961. Chronique d'un été. Direção: Jean Rouch e Edgar Morin. Roteiro: Jean Rouch e Edgar Morin.

Yoon, Soyoung. 2007. “The Cinema, or the Imaginary Man: An Essay in Sociological Anthropology, By Edgar Morin”. Film Quaterly 60(3): 94-95.

\section{Jean Rouch"s "Chronicles of A summer" AND the IDEA of A Shared ANTHRO- POLOGY}

This article examines various aspects of Jean Rouch's documentary and ethnographic filmmaking, particularly as far as concerning his probably most famous work "Chronicles of a Summer" (1961), which he made together with Edgar Morin. For this purpose, Rouch's cinematographic initiative is put in relation to the audiovisual panorama of ethnographic film. The article aims to analyze how Rouch in "Chronicles" thought over the relationship between the representation of the filmic "subject" and "object" within the ethnographic film tradition, thus enriching documentary film with his particular conception of a shared anthropology, at the same time laying the foundations for French "cinéma vérite".

Keywords: visual anthropology, ethnographic film, shared anthropology, cinéma vérité

Recebido em: 2012-11-21

Aceito em: 2013-04-11 